\title{
FACTORS CAUSING HEALTH AND SAFETY HAZARDS AT CONSTRUCTION SITES
}

\author{
Om Prakash Giri \\ Pokhara University \\ Omgi5@yahoo.com
}

\begin{abstract}
The Construction industry is prone to risk to health and safety hazards. Construction workers should have the knowledge of health and safety and apply the knowledge while working. The main objective of this paper was to review and to identify the factors that cause accidents at construction sites and the methods to improve health and safety. The review revealed that lack of awareness about site safety and negligence of workers in wearing Personal Protective Equipment (PPE) were the main causes of poor safety practices. It is necessary to create employer's and contractor's interests in safety management and enhance awareness on possible risk factors to reduce these risk factors among workers. Effective implementation of training and safety awareness programs among construction workers is vital to improve health and safety of construction workers.
\end{abstract}

\section{Key words}

Health and Safety, Safety Hazards, Construction Industry, Accidents.

\section{Introduction}

Construction industry is both economically and socially important for any nation. It plays a vital role to achieve socio-economic development goals by providing infrastructure and employment opportunities [1]. Like many other developing countries the construction industry of Nepal plays an important role to achieve socio-economic development goals and contributing significantly to the gross domestic product (GDP) of the country. However, despite the importance of the industry, it is recognized to be hazardous industry all over the world [2]. The construction industry is experiencing so many risks, uncertainties and complexities due to frequent accidents in the construction projects and its performance in occupational health and safety is not satisfactory. The construction industry employs a large number of workers and those workers need to be controlled by administrators such as managers, contractors and site engineers. Therefore, it is important to train and educate the engineers, contractors and workers and should have proper health and safety plan. It is equally important to follow the safety policy and regulations to reduce the expected and unexpected accidents on construction sites [3].

Safe and hazard free work and work place are needed for higher productivity, efficiency and quality of any industrial process. Among the workplaces high risk or health and safety may occur at the construction sites due to working with machine and equipments, use of electricity, 
use of chemicals, dusty worksites, congested and dark workplace [4]. Therefore, establishing a safe and sound work place environment in construction industry is the important aspect to increase the productivity and enhance the health and safety. Safe and healthy working conditions are the prerequisites to promote development of society at all levels through increasing workers' overall quality of life [5].

Globally as a result of poor occupational health and safety more than 2.78 million people die per year. Additionally, there are some 374 million non-fatal work related injuries and illnesses every year [6]. In developing countries, the risk of having work related injury is 10 to 20 times higher than that of developed counties. This is because in developing countries, majority of the workforce is employed in small and medium scale industries that do not meet the minimum standards and guidelines set by the WHO and the ILO for occupational health and safety.

\section{Occupational Health and Safety in Nepal}

Nepalese construction industry uses low level of mechanization and is more labor intense with inadequate safety regulations [7]. Regulations under Interim constitution 2007, in order to run business employers, need to be abiding by all the OHS rules. Construction industry contributes greatly to the national economy; however, enough initiatives are not taken from concerned bodies to control health and safety hazards in construction sites. Due to lack of law enforcement for labor, majority of accidents are not reported to labor department.

\section{Health and Safety}

Health is the protection of the bodies and minds of people from illness resulting from the materials, processes or procedures used in the workplace. Safety is the protection of people from physical injury. These two words are normally used together to indicate concern for the physical and mental well-being of the individual at the work place. Occupational health and safety has been defined by the International Labor Organization (ILO) [8] as: The prevention and maintenance of the highest degree of physical, mental and social well-being, the prevention of ill-health among workers caused by their working conditions, the protection of workers from factors adverse to their health in their employment, and the placing and maintaining workers in occupational environments.

\section{Construction Industry Health and Safety}

The workers are exposed to hazards of occupational diseases and injuries and the adverse effects of excessively long hours of work. Machines, plants and other construction equipment pose danger to the operators, who in most cases do not have prior skills for operating such machines or plants. A number of factors having a negative impact on health and safety management in Nepal includes poor infrastructure; problems of communication due to low literacy level; unregulated practices on construction sites; traditional methods of working; non availability of equipment; adverse weather conditions; improper use of equipment, etc.

\section{Causes of Accidents}

Accidents do not just happen, they are caused. About 99 percentages of the accidents are caused by either unsafe acts or unsafe conditions or both [9]. Therefore, accidents can be prevented. The unsafe act is a violation of an accepted safe procedure which could permit 
Nepal Engineers' Association, Gandaki

the occurrence of an accident. The unsafe condition is a hazardous physical condition or circumstances which could directly permit the occurrence of an accident. Most accident results from a combination of contributing causes and one or more unsafe acts and unsafe condition.

\section{Health and Safety Measures in Construction}

\section{a. Site Layout and Planning}

A badly planned construction site is the underlying cause of many accidents. This results from falls of materials, collisions between workers and plant, equipment or materials. There are many accidents due to slipping or falling over materials and equipment, space constraints, particularly in urban work sites, etc. Proper planning is an essential part for safe and efficient running of a construction operation.

\section{b. Personal Protective Equipment (PPE)}

Personal protective equipment (PPE) refers to protective clothing, helmets, goggles, safety boots, gloves, safety belts or equipment designed to protect the workers from injury, electrical hazards, heat, chemicals, and infection, for job related occupational health and safety purposes. The PPE required in the construction sites include: eye protection, face protection, hearing protection, respiratory protection, hand and arm protection, foot and leg protection, head protection, body protection and fall protection, etc. PPE are required to reduce employee exposure to hazards when engineering and administrative controls are not feasible or effective in reducing these exposures to acceptable levels [10].

\section{c. First Aid Kits and Accident Reporting} Construction sites are hazardous places, and first aid and rescue equipment should always be available. Types of first aid needed depend on the size of the site and the numbers of employees. On large sites with more than 200 people are employed, there should be a properly equipped first aid room. On any construction site of that size, at least one person on every shift should have been trained in first aid.

\section{d. Health and Safety Warning Signs}

Safety signs and signals are one of the main means of communicating health and safety information. This includes the use of illuminated signs, hand and acoustic signals (e.g. fire alarms), spoken communication, etc. Traditional signboards, such as prohibition and warning signs, signs for fire exits, fire action plan notices and fire-fighting equipment are also considered to be safety signs. For safety signs and signals to be easily understood, care must be taken to avoid using too many signboards in close proximity. Signboards are only effective if they can be seen and understood easily. If too many signs are placed together there is a chance of confusion or important information may be overlooked [11].

\section{e. Safety Policy}

Site managers should have a written safety policy for their enterprises by setting health and safety practices. Construction safety policy therefore must be developed by each site manager and construction company prior to commissioning any construction work.

\section{f. Health and Safety Risk Assessment}

Health and safety risk assessment at a construction site is an important aspect towards reduction of accidents. Employers are required to make an assessment of the health and safety risks to which employees and others are exposed on construction sites [12]. 


\section{g. Health and Safety Training}

With regard to occupational health and safety, training consists of instruction in hazard recognition and control measures, learning safe work practices and proper use of personal protective equipment. Training also provides workers with ways to obtain added information about potential hazards and their control measures. Employees must therefore be given health and safety induction training when they start work. There should also be job specific health and safety training. Training must also be provided if risks change, and refresher training when skills are not frequently used.

\section{h. Working Environment}

Chemical substances are the major health hazards since there are many chemicals used in the construction industry, which include insecticides, adhesives, cleaning agents, wood preservatives, fungicides, and paints, etc. Many of these chemicals are hazardous, with a potential to cause poisoning. Toxic substances can cause both acute and chronic effects resulting from exposure for a long period. Dust from many sources is also a major hazard in construction industry. Silica and asbestos dust can permanently damage the lung tissue. Cement mixes is also a well known cause of skin disease [13].

\section{i. Welfare Facilities}

Work in the construction industry is tough and involves much manual or physical activity. It is also hazardous and dirty and therefore good welfare facilities not only improve workers' welfare but also enhance efficiency. Welfare facilities such as the provision of drinking water, washing, sanitary and changing accommodation, rest rooms and shelter, facilities for preparing and eating meals, temporary housing, assistance in transport from place of residence to the work site and back, all help to reduce fatigue and improve workers' morale and improve health and safety of workers.

\section{Factors Causing Safety Hazards at} Construction Sites

The major accident reasons are as follows $[2,5,10,12]$ :

- Unsafe working conditions.

- Lack of supervision and training.

- Falling from height.

- Falling from scaffolding.

- Falling from ladder

- Falling of an object.

- Accident with machine.

- Use of dangerous chemicals.

- Under water work and dewatering.

- Blasting work.

- Collapse of side wall.

- Falling from edge of excavation.

- Falling of object from edge of excavation.

- Improper lighting and ventilation while carrying out deep excavation work.

- Tripping hazards from construction materials and debris.

- Use of unsafe/defective equipment.

- Operating equipment without authority.

Difficulty to Achieve Sound Health and Safety

Difficulty to achieve sound occupational health and safety in construction industries are $[2,4,5,7,10,12]$ :

- Lack of knowledge and awareness among workers.

- Lack of awareness and commitment in employers and management.

- Lack of protection for people on the ground from falling objects. 
- Management level fear on change and increase in cost.

- Poor consultation system.

- Majority of untrained people both in management and labor.

- No safety-friendly work culture both in workers and management level.

- Lack of research and data-base on occupational health and safety.

- Lack of knowledge and awareness among workers.

- Use of old machinery and equipments.

- Lack of sufficient maintenance of equipments.

- Bad house-keeping practices.

- Violation of safety rules.

\section{Need of Construction Site Safety}

Safety in construction site is needed for the following reasons $[4,12]$ :

- To minimize rate of accident.

- To raise morale of construction workers.

- To increase efficiency of works.

- To improve quality of works.

- To eliminate fatal accident.

- To reduce cost of construction.

\section{Way Ahead for Improvement}

Majority of the construction site accidents can be minimized if appropriate measures are established for the promotion and protection of safety and health of the workers. However, achieving a zero-accident situation may not become possible due to unique nature of construction industry. Health and safety of construction can be made better with healthy human resource, more efficient work, fewer fatalities and lower accident rates through [2, $4,7,10,12]$ :

Hazards identification from the design stages to construction process.

- Isolate workers from harmful substances.

- Developing training modules and formal training and orientation.

- Proper training and refresher training programs should be conducted to educate the workers as well as their supervisors particularly on occupational safety and health.

- Compulsorily introduce induction training for all new workers.

- Provide the stress management program to the workers.

- Motivate workers psychologically to reduce carelessness in using equipmements.

- Formation and mobilization of safety committees in each workplace and enterprises.

- Periodic situational survey, hazard analysis and pre-project planning for health and safety at construction site.

- Introduce safety-incentive programs.

- Provision for safety awards to encourage the workers.

- Health and safety insurance of workers.

- Minimize high employee turnover.

- Sound safety inspection system.

- Safety supervisors should be provided.

- Give major empahis to safety in a construciton project.

- Creating safety regulations and policies.

- Strictly implement health and safety regulations and policies.

- Plan out short and long term safety budgets to ensure the adequacy of safety implementation on site.

- Allocate extra fund for the health and safety so as to prevent the huge loss in the 
future.

- All the individuals related to construction should be aware of Labour Act.

- Regularly check the machinery and conduct periodic maintenance to minimize the accidents caused by machinery failure.

- All the machinery should be properly guarded or fenced.

- Greater attention should be given to the design and selection of tools, equipment and materials.

- Immediate repairing of damaged floors/ surfaces.

- Adoption of good housekeeping practices.

- Involvement of top management and workers in safety issues.

- Management should listen and solve the workers views and problem regarding health and safety.

- Emergency preparedness system should introduce in construction site.

- Provide fist aid box and first aid rooms.

- Appropriate work schedules should be developed and the workers should be assured of their job.

- Increasing in workers awareness of risk factors will be useful to increase the productivity and reduce the risk associated with construction activities.

\section{Conclusion}

Different articles indicate that the factors related to construction site health and safety hazards are unsafe working conditions, lack of supervision and training, unskilled and uninformed about safety measures and equipment to be used, workers are unaware of the type of accidents, workers are being careless with use of safety equipment, employers give less priority to safety and safety management, employers do not invest extra amount of money for safety equipment, programmes of safety training and safety awareness aren't conducted, no provision of safety awards and safety supervisors, not implementation of safety regulation at construction site, workers are unaware of labour act.

To enhance safety practices, an emphasis must be given to enhance interests in active safety management and implementation of awareness programs, which must be developed and implemented among construction workers. An additional training for the workers, which could be provided by contractors about equipment they use, before workers engage in their duty, would also help to prevent and minimize the accidents in construction sites. Therefore, awareness on possible risk factors and knowledge on how to reduce these risk factors among workers and contractors will enhance construction site safety.

\section{References}

1. Anaman, K. A. \& Osei-Amponsah C.,(2007), Analysis Of Causality Links Between The Growth Of The Construction Industry And Growth Of The MacroEconomy In Ghana, Construction Management \& Economics, Vol 25, pp. 951-961.

2. Jannadi, O. A., and Bu-Khamsin, M. S. (2002). Safety factors considered by industrial contractors in Saudi Arabia. Building and Environment, 37(5), 539-547.

3. Central Bureau of Statistics. Report on Nepal Labor Force Survey, 2008. Kathmandu: Central Bureau of statistics; 2009.

4. Upadhyay, U. (2005). Occupational health, safety and environment in the construction 
sector. Issue of the world of work in Nepal. Kathmandu: General Federation of Nepalese Trade Unions.

5. Joshi,S. K., \& Dahal, P. (2009). Occupational health services in Nepal.

6. https://www.ilo.org/global/topics/ safety-and-health-at-work/lang--en/ index.htm

7. Er. Khumraj Pun,2015, Occupational safety and health situation in industrial sector in Nepal. Issue 1, pp 47-54, retrieved 15th December 2018. https://www.scribd. com/doc/50002585/Occupational-safetyand-health-in-industrial- sector-in-nepal.

8. International Labour Office (ILO) (2001). The Construction Industry in the Twenty First Century: Its Image, Employment Prospects and Skill Requirements, Tripartite Meeting on the Construction Industry, Geneva.

9. Ridley, J. (1986) Safety at Work, 2nd Edition. London: Butterworth Ltd.
10. Innovative Solutions to Safety and Health Risks in the Construction, Health Care and HORECA Sectors, European Agency for Safety and Health at Work (EUOSHA),Bilbao,Spain,2011.

11. Health and Safety Executive (HSE). (2009). "Managing Health Risks in Construction", www.hse.gov.uk/construction / designers/index.htm.

12. Health and Safety Executive (HSE). (2004). Improving Health and Safety in the Construction Industry. The Stationery Office, London.International Labour Office (ILO). (1999). Year book of labour statistics. International Labour office, Geneva.

13. International Labour Office (ILO). (1999). Year book of labour statistics. International Labour office, Geneva. 